\title{
Perceptual organization and focused attention: The role of objects and proximity in visual processing
}

\author{
ARTHUR F. KRAMER and ANDREW JACOBSON \\ University of Illinois, Champaign, Illinois
}

\begin{abstract}
The influence of the Gestalt grouping principles of similarity, closure, and proximity on the size of the response-compatibility effect was examined in a focused attention task. In three studies, subjects responded to a centrally located target and attempted to ignore adjacent distractors. The distractors, which served as targets on other trials, could be compatible, incompatible, or neutral with respect to the response of the target. In addition, the distractors and the target could be embedded in the same object, presented in the same color, presented on different objects, or presented in different colors. The typical response-compatibility effect (B. A. Eriksen \& C. W. Eriksen, 1974) was found when the target and distractors were embedded in the same object or presented in the same color. Performance was poorer when the target was surrounded by responseincompatible distractors than when it was surrounded by response-compatible distractors. However, the response-compatibility effect was eliminated when the target and distractors were embedded in different objects, even when the distance between the items was less than $.25^{\circ}$ of visual angle. Furthermore, the response-compatibility effect was of intermediate size when the distractors were not grouped strongly with the target or with neutral flankers. The results are discussed in terms of space- and object-based models of visual attention.
\end{abstract}

In recent years, several different classes of models have been proposed to account for the distribution of attention in the visual field. In the present report, we contrast the predictions of space-based and object-based models of attention in a focused attention paradigm. Space-based models suggest that spotlights, zoom lenses, and gradients provide apt analogies for the allocation of attention. For example, in models that are based on the notion of a spotlight, attention is distributed in contiguous regions of the visual field (Broadbent, 1982; Posner, Snyder, \& Davidson, 1980; Shulman, Remington, \& McLean, 1979; Tsal \& Lavie, 1988). Stimuli that fall within this region or spotlight are extensively processed, while events that occur outside this area are ignored. The requirement to process information in noncontiguous areas of the visual field necessitates movement of the spotlight.

Evidence in support of the spotlight model has been obtained in response competition, spatial priming, and divided attention paradigms. C. W. Eriksen and his colleagues (B. A. Eriksen \& C. W. Eriksen, 1974; C. W. Eriksen \& Hoffman, 1972, 1973) have found that responseincompatible distractors produce large performance costs when they are located within $1^{\circ}$ of visual angle from a

This research was supported by a grant from the Office of Naval Research (N-00014-89-J-1493) monitored by Harold Hawkins. We would like to thank Marie Banich, Charles Eriksen, and Trammell Neill for their helpful comments on a previous draft of the manuscript. Requests for reprints should be addressed to Arthur F. Kramer, Department of Psychology, University of Illinois, 603 East Daniel Street, Champaign, IL 61820 . task-relevant target. On the other hand, distractors have little or no effect when presented at more distant locations. The $1^{\circ}$ radius has been interpreted as the minimal focus of the spotlight in which all stimuli are processed. In spatial priming paradigms, subjects are cued to attend to a particular location in the visual field. When a stimulus occurs at the cued location, responses are fast and accurate. However, if a stimulus occurs at an uncued location, performance declines (Bashinski \& Bacharach, 1980; Podgorny \& Shepard, 1983; Posner, 1980; Remington $\&$ Pierce, 1984; Shulman et al., 1979). These effects have been interpreted in terms of the spotlight model; the performance costs associated with the stimuli at the uncued locations are attributed to the requirement to reorient the spotlight. Finally, a number of divided attention studies have revealed enhanced performance when the stimuli are located in close spatial proximity (Hoffman, Houck, MacMillan, Simons, \& Oatman, 1985; Hoffman \& Nelson, 1981; Kramer, Wickens, \& Donchin, 1985), suggesting that attention is distributed over a restricted area of visual space.

The zoom-lens and gradient approaches have been proposed to accommodate recent findings which suggest that, depending on subject strategies and task demands, efficient processing can occur over either a narrow or a wide area of visual space (Gatti \& Egeth, 1978; Jonides, 1983; LaBerge, 1983; LaBerge \& Brown, 1986). Within the zoom-lens model (C. W. Eriksen \& St. James, 1986; C. W. Eriksen \& Yeh, 1985), attention can be dynamically allocated along a continuum from tightly focused to widely distributed. The resolution of the attentional sys- 
tem is inversely related to the width of the attentional beam. Thus, with difficult discriminations, a concentrated beam of attention with high resolving power would be necessary for successful processing of the stimulus array. On the other hand, relatively easy discriminations could be made with attention distributed across the visual field (see Duncan \& Humphreys, 1989; Treisman \& Gormican, 1988; Wolfe, Cave, \& Franzel, 1989, for additional support for the dynamic nature of visual attention).

Similar to the zoom-lens model, gradient models suggest that processing efficiency varies over the visual field (Andersen, 1990; Downing, 1988; Downing \& Pinker, 1985; Hughes \& Zimba, 1985; Mangun \& Hillyard, 1987). In gradient models, however, the attentional focus does not shift from narrowly to widely distributed areas; rather, processing efficiency decreases in a continuous fashion from the center to the periphery of the attentional field. It has also been suggested that the gradient of sensitivity depends on the type of information that is processed and the spatial distribution of that information (Downing, 1988; LaBerge \& Brown, 1989).

Although in each of the space-based models a different mechanism accounts for the changes in processing efficiency across the visual field, in all of them space plays a primary role in controlling attention. These space-based models can be contrasted with object-based models of visual attention. In object-based models, space or physical proximity is no longer the dominant factor in the control of attention; other grouping factors, such as contour, color, and movement, also influence the distribution of attention. These models are descendants of earlier research and theorizing of Gestalt psychologists who argued for the role of perceptual organization in visual and auditory processing (Wertheimer, 1923). One such attentional model was proposed by Neisser (1967). In the first stage of the model, the visual field is preattentively segmented into separate figural units or objects on the basis of Gestalt properties such as continuity, proximity, similarity, and movement. In the second stage, focal attention is employed to analyze specific objects in more detail. More recently, Kahneman and his colleagues (Kahneman \& Henik, 1977, 1981; Kahneman \& Treisman, 1984; Kahneman, Treisman, \& Burkell, 1983; Treisman, Kahneman, \& Burkell, 1983; see also Duncan, 1984; Duncan \& Humphreys, 1989; Kramer et al., 1985; Neisser \& Becklen, 1975; Rock \& Guttman, 1981) have also argued that attention operates on perceptual units or objects that are organized by preattentive processes. The focusing of attention on a particular object results in the mandatory proessing of all attributes of that object. Thus, different attributes of an object are processed in parallel, whereas different objects are processed serially.

The theoretical assumptions of the object-based models have implications for both focused and divided attention tasks. In the case of a focused attention task, performance should improve to the degree that conflicting information and relevant information can be located on different objects. On the other hand, performance on divided atten- tion tasks should be best when all of the information can be located on a single object.

Two lines of evidence have provided support for objectbased models of attention. One area of research concerns the effect of perceptual grouping on selective and divided attention. In these studies, attentional processes have been influenced by perceptual groups formed by color, movement, and the interactions of positions, orientations, and shapes of line segments (Banks, Bodinger, \& Illige, 1974; Banks \& Prinzmetal, 1976; Beck \& Ambler, 1973; Driver \& Baylis, 1989; Harms \& Bundesen, 1983; Humphreys, 1981).

Support for object-based views has also been obtained in studies of the degree to which subjects' reports of several attributes can be improved when the attributes are located on the same object. Lappin (1967) had subjects identify three attributes of a single object, three different attributes on three objects, or the same attribute on three different objects. Consistent with the predictions of objectbased models, performance was best when subjects identified three attributes on a single object (see also Yntema, 1963). More recently, Treisman et al. (1983) required subjects to report the location of a gap in a rectangular frame while also reading a tachistoscopically presented word; the word was located either inside, presumably forming a perceptual object, or next to the frame. Reading and gap detection times were significantly faster when the word was located within the frame. Finally, Duncan (1984) reported a series of studies in which subjects were presented with two superimposed objects and were required to identify either two dimensions of a single object or one dimension on each of the objects. Performance was best when both of the dimensions were on the same object. In summary, in each of the divided attention tasks discussed above, performance was superior when dimensions were identified on a single object.

It is interesting that although space-based and objectbased models suggest that attention is distributed on the basis of different principles, the differentiation between these models is complicated by the fact that objects occur in space. Two objects are usually located at greater distances from each other than are two properties of a single object. In this case, the predictions of the two classes of models would be the same, since objects and space covary. Therefore, a convincing test of these models would require that either proximity or objects be held constant as the other factor is manipulated.

A confound between spatial proximity and object relations can be found, to varying degrees, in the studies described above. For example, in the Lappin (1967) study, the information to be extracted from the display was more widely distributed in the different-object conditions than in the same-object conditions (see also Yntema, 1963). In the Treisman et al. (1983) study, the visual angle between the word and the rectangular frame was equivalent in the same- and different-object conditions. However, even though the visual angle between the stimuli was constant, the area of visual space occupied by the stimuli 
differed in the two conditions. When the frame surrounded the word, only the space within the frame was relevant, whereas the space occupied by the word and the frame on both sides of fixation was relevant in the differentobject condition. Duncan (1984) superimposed two objects, a box and a line, in an effort to unconfound spatial proximity and object relations. However, information concerning the two dimensions of the line-texture and slantcould be obtained from the same location, whereas information concerning some of the dimensions in the differentobject condition (i.e., the size of the box and the texture or slant of the line) was more widely distributed.

In an effort to eliminate the confound between object relations and spatial proximity, we constructed a set of stimuli (see Figure 1) in which object relations were

Compatible
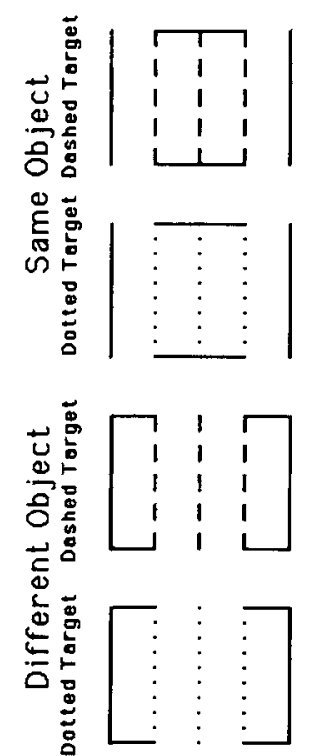

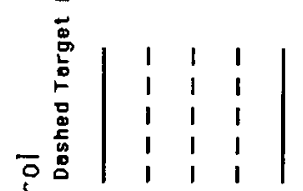

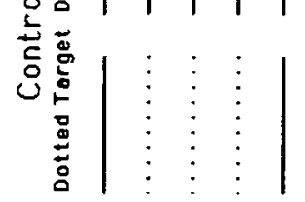

Figure 1. A graphic illustration of the stimuli used in the experiments. In the same-object condition in Experiment 1, the three inner vertical lines and the two horizontal lines were presented in the same color while the two solid vertical lines were presented in another color. In the different-object condition in Experiment 1, the center vertical line was presented in one color while the other vertical and horizontal lines were presented in another color. All of the lines were presented in the same color in the control condition. In Experiment 2, the same color coding scheme was used; but the horizontal lines were removed. Finally, in Experiment 3, all of the lines were presented in the same color. varied while the spatial proximity of targets and flankers was held constant. The subjects were instructed to respond to a centrally located target and ignore the flankers. The subjects made one response if a dotted line was the target and another response if a dashed line was the target. The flankers could be either compatible or incompatible with the response to the target; the flankers and the target were either embedded in the same object (rows 1 and 2 of Figure 1) or in different objects (rows 3 to 6 of Figure 1). In addition, in the different-object conditions, the distractors could either be strongly grouped with the other items in the display, through the use of common contour and color (rows 3 and 4 of Figure 1), or weakly grouped with the other items (rows 5 and 6 of Figure 1).

Object-based models predict that the size of the responsecompatibility effect, the difference in reaction time and accuracy in the response-compatible and -incompatible conditions, will be influenced by whether the distractors and the target are located on the same object or on different objects or perceptual units. Given a fixed spatial separation between the target and distractors, the "costs" associated with the response-incompatible distractors should decrease when these stimuli and the targets are located on separate objects (rows 3 to 6 of Figure 1), relative to trials on which the target and distractors are embedded in the same object (rows 1 and 2 of Figure 1: Duncan, 1984; Kahneman \& Henik, 1981; Treisman et al., 1983).

On the other hand, space-based models, in which grouping factors other than proximity do not influence selection, predict that the size of the response-compatibility effect will depend on the separation between the target and the distractors. Therefore, given fixed spatial separations between the target and distractors, there should be no difference in the magnitude of the responsecompatibility effect as a function of whether the distractors and the target are located on the same object or on different objects (Broadbent, 1982; Downing \& Pinker, 1985; Tsal \& Lavie, 1988).

A second issue investigated in the present series of experiments concerns the question of whether grouping should be viewed as a continuum or in terms of qualitative differences between objects or perceptual units (Duncan, 1984). In the former case, the size of the responsecompatibility effect should depend, in a graded fashion, on the strength of grouping in the displays. In the latter case, the response-compatibility effect should be small or absent as long as the target and distractors are located on separate objects, and large when they are located on the same object. This issue will be addressed in the present experiments through comparison of the size of the response-compatibility effect obtained in the differentobject conditions (rows 3 and 4 in Figure 1) with the response-compatibility effect obtained in the control condition (rows 5 and 6 of Figure 1). In both the differentobject and control conditions, the distractors are distinct from the target. Therefore, an object-based model that endorses a qualitative distinction between objects or perceptual units would predict similar response-compatibility 
effects in the two conditions. However, if grouping of the response-compatible or response-incompatible distractors with the neutral flankers (i.e., solid vertical lines) is stronger in the different-object conditions, due to common contour (Experiments 1 and 3) and color (Experiments 1 and 2), a grouping strength model would predict a smaller response-compatibility effect in the differentobject conditions than in the control conditions. Furthermore, we would also expect that since grouping of the target and distractors is strongest in the same-object conditions, the response-compatibility effect should be largest in the same-object condition, of intermediate size in the control condition, and smallest in the different-object condition.

The examination of the issue of graded versus qualitative grouping requires converging evidence for our rankings of the displays in terms of strength of grouping. To this end, we had two different groups of subjects indicate the groups or objects that they perceived in each of the displays and rate the strength of grouping in each display. One group of subjects participated in the task and rated the displays later, whereas the other group of subjects rated the displays but did not perform the focused attention task. The methods used to obtain these ratings are described in detail in the Procedure section of Experiment 1.

A third issue that we explored was the influence of spatial proximity on the magnitude of the response-compatibility effect. According to space-based models, the responsecompatibility effect will decrease as the physical proximity between the target and the distractors decreases. An empirically defined limit of $1^{\circ}$ of visual angle has been suggested as representing the minimal focus of attention in which all stimuli are processed (B. A. Eriksen \& C. W. Eriksen, 1974). On the other hand, performance in objectbased models depends on the nature of the task (e.g., divided versus focused attention tasks) and on whether information is located on the same or on different objects. Given that the objects can be easily recognized, the size of the objects should not be critical in the determination of the size of the response-compatibility effect. We examined this issue by creating displays in which distractors were located within $25^{\circ}$ or $1^{\circ}$ of visual angle from the target.

\section{EXPERIMENT 1}

In the studies that have provided evidence for objectbased models of attention, same- and different-object conditions have been distinguished on the basis of contour (Duncan, 1984; Kramer et al., 1985; Lappin, 1967; Treisman et al., 1983; Yntema, 1963). However, ample evidence suggests that properties other than contour can influence performance in focused and divided attention paradigms. For example, Harms and Bundesen (1983; see also Humphreys, 1981) found that the response-compatibility effect could be influenced by color-coding targets and distractors. The negative impact of the response-incompatible distrac- tors was reduced by presenting the targets and distractors in different colors. Other studies have shown that attentional processes can be influenced by perceptual groups formed by interactions of positions, orientations, and shapes of line segments (Banks et al., 1974; Banks \& Prinzmetal, 1976; Beck \& Ambler, 1973; Pomerantz \& Pristach, 1989; Pomerantz \& Schwaitzberg, 1975). For instance, O'Hara (1980; see also O'Hara \& Eriksen, 1979) discovered that the interference from extraneous letters in a same-different matching task could be minimized by arranging the extraneous letters to form familiar words. Finally, movement has also been shown to influence the distribution of attention. Driver and Baylis (1989) found that when response-incompatible distractors moved in the same direction and with the same velocity as a target did, they produced larger performance costs than did stationary distractors that were more proximate to the target (see also Tipper, Brehaut, \& Driver, 1990).

In an effort to investigate the correspondence between object-based effects and more general grouping phenomena, we examined the combined and separate influence of two different principles of grouping-closure and similarity (Wertheimer, 1923) - on the response-compatibility effect. These grouping principles were instantiated in the displays through the use of contour and color, respectively. These specific grouping principles were examined for the following reason. It might be argued that any changes in the magnitude of the response-compatibility effect as a function of whether or not the target and distractors share the same color may be due to changes in confusability rather than to perceptual grouping. However, the confusability interpretation would seem less plausible if contour was added to the display, since this manipulation does not directly modify the target or distractors. Thus, a comparison of the combined effects of contour and color (Experiment 1) with their independent effects (Experiments 2 and 3) on response-compatibility performance should provide some insight into the mechanisms underlying different Gestalt principles of grouping.

\section{Method}

Subjects. Twelve right-handed students, 5 males and 7 females, from the University of Illinois participated in the study. The subjects ranged in age from 18 to 22 . All had normal or corrected-tonormal vision and obtained a perfect score on the Ishihari Color Blindness Test (1989). The subjects were paid $\$ 4.50$ per hour for their participation.

Stimuli and Apparatus. The stimuli are graphically illustrated in Figure 1. They were presented on an IBM EGA monitor driven by an IBM XT computer. The vertical line in the center of each display was defined as the target; all other vertical and horizontal lines were distractors. The subjects were to make one response if a dotted line was the target and another response if the target was a dashed line. The subjects depressed the " $S$ " and " $L$ " keys on an IBM keyboard to make their responses. Response key ("S" or " $L$ ") was counterbalanced across subjects. Response time was accurate to $1 \mathrm{msec}$.

The subjects viewed the stimuli binocularly at a distance of $130 \mathrm{~cm}$. The use of a chinrest ensured this fixed distance, at which each of the vertical lines subtended a visual angle of $.90^{\circ}$ vertically and $.10^{\circ}$ horizontally. The vertical lines were presented at 
two different separations. In the near condition, the flankers were separated from the target line by $.25^{\circ}$ of visual angle. Thus, the horizontal extent of the display in the near condition was approximately $1.0^{\circ}$ of visual angle. In the far condition, the flankers were separated from the target by $1.0^{\circ}$ of visual angle. Thus, the horizontal extent of the far condition was $4.0^{\circ}$.

In order to create different perceptual objects, we used color redundantly with the interconnecting horizontal lines. Thus, in the same-object condition, the target, near distractors, and horizontal lines were presented in one color, while the solid vertical lines were presented in another color. In the different-object condition, the target was presented in one color, while the other vertical and horizontal lines were presented in another color. In the control condition, which is portrayed in the two bottom rows of Figure 1, all of the vertical lines were presented in the same color. Henceforth, this control condition will be referred to as the multiple-stimulus (MS) control. In a second control condition, only the target was presented (the single-stimulus, or SS, control). The colors used in the displays were EGA red and green. A subjective comparison of these colors with the Munsell color chips yielded the following Munsell values: for red, hue $=5 R$, value $=6$, chroma $=10$; for green, hue $=10 G Y$, value $=6$, chroma $=10$. The stimuli were presented in red on half of the trials and in green on the other trials. The background color was light gray.

Procedure. The experiment was performed in three sessions over a period of 3 consecutive days. During each session, which lasted approximately $90 \mathrm{~min}$, the subjects performed 30 blocks of 52 trials. The first session and the first block of Sessions 2 and 3 were considered practice and will not be discussed. Each block comprised equal numbers of same-object, different-object, and MS control trials; near conditions and far conditions; compatible trials and incompatible trials; dashed and dotted targets; and red and green targets. Four SS control trials were also presented in each block (dashed/ dotted $\times$ red/green targets).

The subjects' task was to press one response button if a dashed target was present or another response button if the dotted target was displayed. The target item always appeared in the center of the display. The task was self-paced. The subjects depressed the space bar to begin each trial. A fixation cross then appeared; it was displayed for $200 \mathrm{msec}$. Following the offset of the fixation cross, the stimulus display was presented; it remained on the screen until the subject responded.

The subjects received feedback on their accuracy and response time (in milliseconds) following each trial. Following each block of trials, the subjects were presented with a historical summary of their average reaction times and accuracy for each of the preceding blocks. This trend information was displayed graphically. The subjects were instructed to respond as fast as possible while maintaining above $90 \%$ accuracy.

At the conclusion of the study, the subjects were asked to (1) indicate the groups or objects that they perceived in each of the displays (i.e., 48 displays, formed by 2 distances $\times 2$ levels of compatibility $\times 3$ object conditions $\times 2$ target line types $\times 2$ colors), (2) rate the strength of grouping in each display on a 7-point bipolar scale $(1=$ weak grouping, $7=$ strong grouping $)$, and (3) indicate the degree to which they used each of the cues (contour and color) to help them distinguish the target from the distractors. In the cue-utilization rating procedure, each of the cues was rated separately on a 7 -point bipolar scale $(1=$ didn't use the cue, $7=$ always used the cue ). To rate the groups, the subjects viewed the stimuli on the same display that had been used in the experiment and circled the "groups" on a sheet of paper that mimicked the CRT display. The strength-of-grouping rating was also obtained while the subjects viewed the display. Prior to completing the rating procedures, the subjects viewed each of the experimental stimuli on the CRT
Experimental design. The experiment was a within-subjects three-way factorial. The factors included compatibility (compatible and incompatible flankers), distance (near and far), and object type (same-object, different-object, and MS control conditions). There were also equal numbers of dashed and dotted targets. Color and contour were used to redundantly code the same- and different-object conditions. In the control conditions, the stimuli were green on half of the trials and red on the other half of the trials. The order of trials within each block was randomized.

\section{Results}

The mean correct reaction time (RT) and percent correct values are presented in Figure 2 and Table 1, respectively. The RTs and accuracies were subjected to threeway repeated measures analyses of variance (ANOVAs; distance $\times$ compatibility $\times$ object type). The data have several noteworthy aspects. First, targets that were surrounded with response-incompatible items resulted in longer RTs $[F(1,11)=6.6, p<.05]$ and lower accuracies $[F(1,11)=14.9, p<.01]$ than did targets that were surrounded by response-compatible items. This pattern of data replicates the often reported response-compatibility effect (B. A. Eriksen \& C. W. Eriksen, 1974). A significant main effect was also obtained for distance; RTs decreased $[F(1,11)=19.7, p<.01]$ and accuracies increased $[F(1,11)=20.1, p<.01]$ from the near to the far conditions. Furthermore, target-distractor compatibility and distance interacted significantly [for RT $F(1,11)$ $=31.9, p<.01$, and for accuracy, $F(1,11)=10.1, p<$ .01 ]; the response-compatibility effect diminished with increasing distance between the target and distractors. Differences in RT between the response-compatible and response-incompatible conditions decreased from 18.6 to $6.3 \mathrm{msec}$, and accuracy differences decreased from $4.5 \%$ to $.7 \%$.

Given that we have demonstrated that the responsecompatibility effect was obtained, the most important data with regard to our original hypotheses is the relationship between response compatibility and the object factor. As can be seen in Figure 2 and Table 1, the compatibility effect was largest for the same-object condition, somewhat smaller in the MS control condition, and smallest in the different-object condition. This observation was confirmed by the significant two-way interaction between the compatibility and object factors [for RT, $F(2,22)=$ $21.6, p<.01$; for accuracy, $F(2,22)=12.8, p<.01]$. Differences in RT between the response-compatible and response-incompatible conditions decreased from $23.5 \mathrm{msec}$ in the same-object condition, to $11.5 \mathrm{msec}$ in the MS control condition, to $3.5 \mathrm{msec}$ in the differentobject condition. For the accuracy measure, the responsecompatibility effect declined from $3.9 \%$ in the same-object condition, to $2.6 \%$ in the MS control condition, to $1.4 \%$ in the different-object condition. Post hoc comparisons indicated that the differences between the responsecompatible and response-incompatible conditions were significant for the same-object and MS control conditions but not for the different-object condition for RT and ac- 


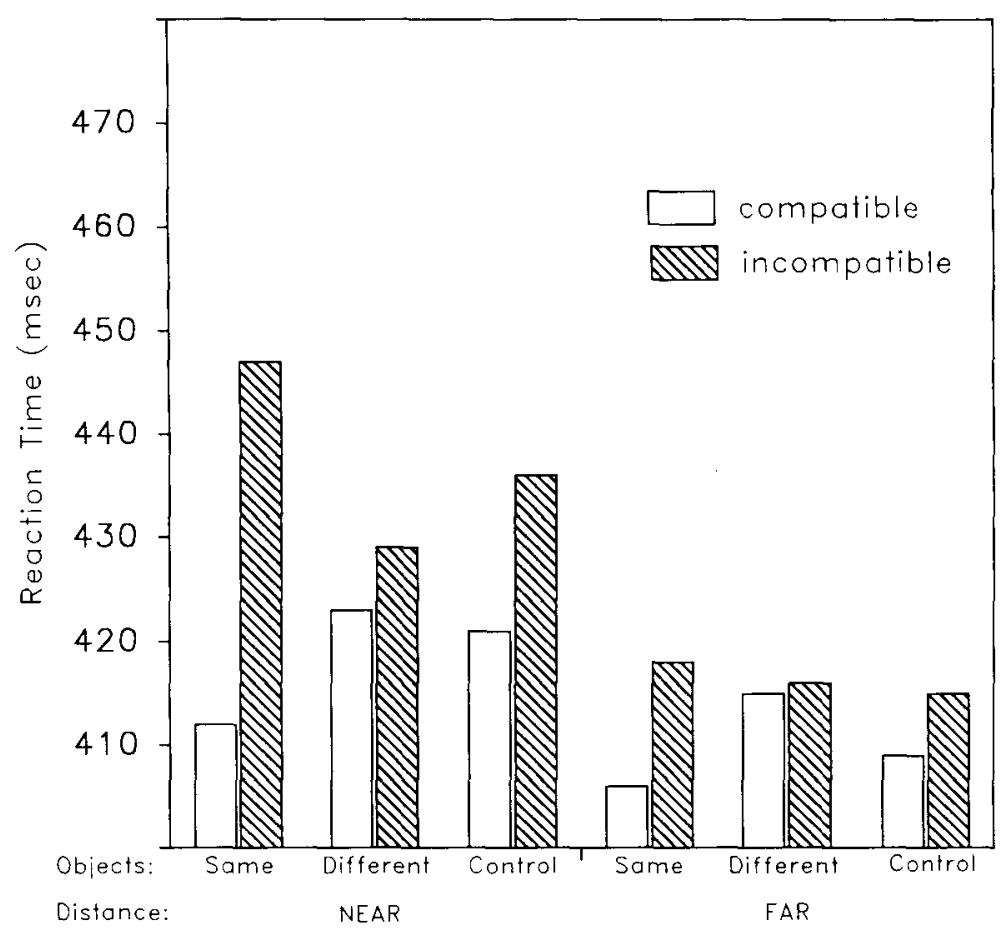

Figure 2. Average correct reaction times for each of the conditions in Experiment 1.

curacy $(p s<.05) .{ }^{1}$ Furthermore, the differences between the same- and different-object conditions can be attributed to both increased RTs and decreased accuracies for the response-incompatible trials and decreased RTs and increased accuracies for the response-compatible trials in the same- as opposed to the different-object condition $(p s<.05)$. The average RT and accuracy in the SS control condition were $408 \mathrm{msec}$ and $95.1 \%$, respectively.

The subjects' designation of the number of groups in each display conformed to our hypotheses about grouping. Three groups were indicated in the same- and differentobject displays. In the same-object condition, the neutral flankers formed two separate groups, while the target, near distractors, and horizontal lines were viewed as another group. In the different-object condition, the near distractors, horizontal lines, and neutral flankers formed a group on each side of the display, while the target was viewed as another group. Five separate groups, one for each of the vertical lines, were indicated in the MS control condition. Each of the subjects indicated the same grouping structure.
The strength of grouping ratings were submitted to a three-way repeated measures ANOVA (compatibility $x$ distance $\times$ object type). The mean strength rating across conditions was $5.6(1=$ weak grouping, $7=$ strong grouping). The only significant effect was due to object type $[F(2,22)=16.3, p<.01]$. The same- $(5.9)$ and different-object displays (6.0) were viewed as more strongly grouped than the MS control displays (4.9). Finally, a repeated measures ANOVA was also performed on the cue-utilization data. One main effect achieved statistical significance. The subjects indicated that they used the color cue more frequently than they used the contour information $[6.3$ vs. $5.1: F(1,11)=14.2, p<.01] .^{2}$

\section{Discussion}

The results obtained in Experiment 1 provide support for both object- and space-based models of visual attention. Consistent with predictions of object-based models, the response-compatibility effect was larger when the target and distractors were located on the same object than when the target and distractors were located on differ-

Table 1

Mean Percent Correct Scores for Each of the Conditions in Experiment 1

\begin{tabular}{lccccccc}
\hline & \multicolumn{3}{c}{ Response-Compatible } & & \multicolumn{3}{c}{ Response-Incompatible } \\
\cline { 2 - 3 } \cline { 6 - 8 } Distance & Same & Different & & & Same & Different & \\
Object & Object & Control & & Object & Object & Control \\
\hline Near & 94.9 & 92.7 & 93.6 & & 88.3 & 90.1 & 89.2 \\
Far & 95.7 & 95.1 & 94.8 & & 94.5 & 94.9 & 94.1 \\
\hline
\end{tabular}


ent objects. In fact, the response-compatibility effect was both small and nonsignificant in the different-object condition. Thus, it appears that even when targets and distractors are located in close physical proximity, within $.25^{\circ}$ of visual angle, structural aspects of the display such as contour and color can have substantial effects on subjects' ability to successfully focus attention on a subset of the stimuli.

Graded versus all-or-none grouping. The present results are also relevant to the issue of whether grouping should be viewed as a continuum or in terms of qualitative differences between perceptual units or objects. The qualitative model predicted similar response-compatibility effects in the different-object and MS control conditions, because the target and distractors were located on separate objects in both of these conditions. On the other hand, the grouping strength model predicted that the magnitude of the response-compatibility effect would decline from the same-object, to the MS control, to the different-object condition. It was hypothesized that the target and distractors would be most strongly grouped in the same-object condition because of common contour and color. It was also expected that the target and distractors would be least strongly grouped in the different-object condition, because the target and distractors were located on different objects and presented in different colors. Finally, it was hypothesized that grouping of the target and distractors would be of intermediate strength in the MS control condition, because the distractors, the target, and the neutral flankers had the same color. Our ranking of the displays in terms of the number of groups and the strength of grouping was supported by two independent groups of subjects, one group who performed the focused attention task and another group who completed the ranking procedure without performing the focused attention task.

The finding that the magnitude of the responsecompatibility effect was largest in the same-object condition, somewhat smaller in the MS control condition, and smallest in the different-object condition suggests that grouping may be viewed in terms of a quantitative metric of strength rather than a qualitative distinction between objects. ${ }^{3}$ Thus, it would appear that designation of objects per se is insufficient to predict focused attention effects. However, at present it is unclear how grouping strength should be measured or scaled. In the current situation, it appears that the subjects' ranking of grouping strength was based on a simple relative similarity rule, by which the contour and color cues were weighted equally. Displays in which target and distractors shared the same color and contour but differed in color and contour from other stimuli in the display (i.e., neutral vertical lines) were rated as strongly grouped. Conversely, if the target and distractors did not share the same color and contour but the distractors shared color and contour with other stimuli in the display, the target and distractors were rated as weakly grouped. Finally, grouping of the target and distractors was rated intermediate in strength if the distractors, the target, and the neutral flankers were presented in the same color.
It is important that the subjects in Experiment 1 could have used color, contour, or both cues on which to base their rankings of grouping strength. Furthermore, the pattern of performance effects could be due to either perceptual grouping or changes in the relative confusability of the target and distractors. In Experiments 2 and 3, we further explored the issue of grouping strength, by investigating whether the same rankings and graded pattern of response-compatibility effects would be supported by the independent application of the principles of similarity and closure.

Facilitation and interference during grouping. Another interesting issue that can be addressed, in part, with the present data is the nature of the changes in the response-compatibility effect as a function of grouping. Previous research has suggested that with simultaneous presentation of the target and distractors, the responsecompatibility effect is primarily due to increased RTs and decreased accuracies in the incompatible response conditions relative to a "neutral" baseline condition (C. W. Eriksen \& Schultz, 1979; Flowers \& Wilcox, 1982; Grice \& Gwynne, 1985). Although there have been some reports of decreases in RT and increases in accuracy in responsecompatible conditions with the simultaneous presentation of the target and distractors (Gatti \& Egeth, 1978; Harms \& Bundesen, 1983; Humphreys, 1981), the general consensus is that these effects are only reliable when the distractors precede the target by approximately $100 \mathrm{msec}$ (Grice \& Gwynne, 1985). Although the asymmetric nature of facilitation and interference in the responsecompatibility paradigm is not fully understood, it has been suggested that the compatible response condition may produce both facilitation and interference, owing to visual filtering, and that it therefore may cancel any potential benefits to performance (B. A. Eriksen \& C. W. Eriksen, 1974; Treisman et al., 1983; Yeh \& C. W. Eriksen, 1984).

In Experiment 1, we observed increases in RT and decreases in accuracy in the response-incompatible conditions in the same-object relative to the different-object condition, as well as decreases in RT and increases in accuracy in the response-compatible conditions in the sameobject relative to the different-object condition. Thus, it would appear that the processes underlying both interference and facilitation were influenced by the grouping manipulation. However, an important issue in determining costs and benefits in performance concerns the selection of the proper neutral or baseline condition (Jonides \& Mack, 1984). If we treat the MS control condition as the baseline, then both facilitation and interference are obtained for the same-object condition. On the other hand, if we use the SS control condition as the baseline (singletarget presentation), only interference effects are obtained, and response-compatible trials are not significantly faster or more accurate than responses in the SS control condition.

What have we learned with regard to the processes of facilitation and interference? First, it appears that perceptual grouping can amplify both costs and benefits in a graded fashion. Changes in the response-compatibility effect as a function of grouping strength could be attributed 
to both increased RTs and decreased accuracies in the response-incompatible conditions as well as to decreased RTs and increased accuracies in the response-compatible conditions. Second, even with the grouping manipulation, facilitation effects are not obtained relative to a singletarget baseline (SS condition). Thus, the presumed filtering costs that are associated with locating a target among distractors, and even a target that is precued and spatially invariant, are quite robust and insensitive to grouping phenomena.

Within-object proximity effects. It is interesting that although the pattern of results for the same- and differentobject conditions was maintained across the near and far distances, the magnitude of the response-compatibility effect was reduced from the $.25^{\circ}$ to the $1^{\circ}$ condition. How might such an effect be interpreted by space-based and object-based models? Space-based models predict that both the benefits and costs of flankers should be reduced as they are moved farther apart. In support of this prediction, it has often been shown that the response-compatibility effect is absent at separations of greater than $1^{\circ}$ of visual angle (B. A. Eriksen \& C. W. Eriksen, 1974; C. W. Eriksen \& Hoffman, 1972, 1973). On the other hand, object-based models suggest that the costs and benefits should depend on how the stimuli are grouped. The subjects reported the same number of "groups" and the same grouping strength at both the near and far distances. Thus, it appears that object-based models can account for the data obtained at the near distance, whereas space-based models provide a better account of the results obtained at the far distance.

It might be argued, however, that given the differences in acuity between $.25^{\circ}$ and $1^{\circ}$, it cannot be unequivocally determined whether the reduced response-compatibility effects were due to a failure of the object-based models or to decreased acuity. Although acuity may play a role in the reduced RTs and increased accuracies in the far conditions, several arguments suggest that differences in acuity may not account for the entire effect. First, decreases in the response-compatibility effect as a function of target-distractor separation have been found in the absence of acuity differences (B. A. Eriksen \& C. W. Eriksen, 1974). Second, our distractors were clearly distinguishable at a distance of $1^{\circ}$ of visual angle from fixation. In fact, our flankers were 10 times larger than the recognition threshold for similar stimuli (Anstis, 1974; Ludvigh, 1941; Weymouth, 1958). Finally, and most importantly, a pilot study that we conducted to examine possible changes in the discriminability of the stimuli at the $.25^{\circ}$ and $1^{\circ}$ locations produced nonsignificant RT and accuracy effects. In the pilot study, 8 subjects made one response if they saw a dashed vertical line in the display and another response if a dotted line was present in the display. On each trial, the subjects were presented with a fixation cross followed by either a dashed or a dotted vertical line at either $.25^{\circ}$ or $1^{\circ}$ from fixation on the right or left side of the display. These vertical lines were identical to those in Experiment 1. Each subject performed three blocks of 160 trials.
The mean RTs and accuracies differed by less than $4 \mathrm{msec}$ and $.4 \%$ at the near and far distances. These small and nonsignificant differences between near and far conditions suggest that the reduced response-compatibility effects in the same-object condition in Experiment 1 cannot be attributed to acuity differences between the $.25^{\circ}$ and $1^{\circ}$ separations. Instead, it appears that in focused attention tasks in which the location of the target is fixed, subjects are capable of directing attention to areas smaller than $1^{\circ}$ of visual angle, despite the presence of perceptual units or objects that would promote grouping if attention were more widely distributed.

\section{EXPERIMENT 2}

In Experiment 1, we distinguished between same- and different-object conditions on the basis of contour and color information, thereby invoking the Gestalt grouping principles of closure and similarity, respectively (Wertheimer, 1923). In the same-object conditions, the target and the distractors were displayed in the same color, and the target was also connected to the distractors by horizontal lines, thereby creating a rectangle. In the differentobject conditions, the distractors and target differed in color, and the distractors were connected to the neutral flankers. Although redundant coding clearly had a strong influence on the response-compatibility effect, as evidenced by both the performance and the subjective rating measures, the results obtained thus far did not permit us to determine the independent role of similarity and closure in the focused attention task. In Experiments 2 and 3, we examined the contributions of similarity and closure to the grouping phenomena by distinguishing between same- and different-object conditions with a single cue. Experiment 2 was focused on color, whereas Experiment 3 was focused on the role of contour in the sameand different-object effects.

Why is it important to determine whether closure and similarity have the same impact on performance in our focused attention paradigm? There are at least two answers to this question.

First, as has been discussed earlier, the fact that the principles of similarity and closure are implemented in different ways may lead to different interpretations of their effects. In the case of similarity, the target and distractors are modified by changing their color across conditions. Therefore, it is possible that performance effects may be a function of changes in the relative discriminability of the stimuli, rather than changes in perceptual grouping; similarly colored stimuli might be more visually confusable than differently colored stimuli. However, in the case of closure, changes in the same- and differentobject conditions are accomplished without directly modifying the target and distractors. Thus, a confusability interpretation of performance effects would appear to be less plausible with the closure principle.

The second answer concerns the research that has been conducted to examine the distinction between object- and space-based models of visual attention. In this research, 
for the most part, contour information has been used to code different objects (Duncan, 1984; Kramer et al., 1985; Lappin, 1967; Treisman et al., 1983; Yntema, 1963). Although contour is certainly an important code for objectness, objects can also be identified on the basis of other cues, such as shading, color, or movement. Thus, the comparison of the contour and color cues in the present experiments can enable us to determine the general relevance of the object-based effects to cues other than contour. This comparison should also be useful as a beginning in the attempt to bridge the gap between the investigation of object-based models of attention and research on grouping phenomena in other domains such as visual search, partial report, form discrimination, and texture segregationin which a wider variety of cues have traditionally been employed (Banks \& Prinzmetal, 1976; Beck, 1982; Beck \& Ambler, 1973; Bundesen \& Pedersen, 1983; Egeth, Virzi, \& Garbart, 1984; Fryklund, 1975; Garner, 1987; Pomerantz \& Pristach, 1989).

\section{Method}

Subjects. Twelve right-handed subjects, 5 males and 7 females, participated in the study. The subjects ranged in age from 19 to 24. All had normal or corrected-to-normal vision and obtained a perfect score on the Ishihari Color Blindness Test. The subjects were paid $\$ 4.50$ per hour for their participation.

Stimuli and Apparatus. The stimuli were identical to those used in Experiment 1, with the exception that the different levels of the object manipulation were defined by color without the use of the interconnecting horizontal lines. Thus, in the same-object condition, the target and the two distractors were presented in one color and the neutral (solid) lines were presented in the other color. In the different-object condition, the distractors and the neutral lines were presented in one color and the target was displayed in the other color. Finally, in the MS control condition, all of the vertical lines were presented in the same color.

Procedure. The procedure was equivalent to that in Experiment 1.

Experimental design. The experiment was a within-subjects three-way factorial. The factors included compatibility (compatible and incompatible flankers), distance (near and far), and object type (MS control, same and different objects). Color was used to code the same- and different-object conditions. In the control condition, the stimuli were green on half the trials and red on the other half of the trials. The order of trials was randomized within each block.

\section{Results}

The mean correct RT and percent correct scores are presented in Figure 3 and Table 2, respectively. Threeway repeated measures ANOVAs (distance $\times$ compatibility $\times$ object type) showed that RTs were longer and accuracies lower in the response-incompatible as opposed to the response-compatible conditions [for RT, $F(1,11)$ $=20.6, p<.01$; for accuracy, $F(1,11)=8.4, p<.01]$ and with the near as opposed to the far distractor distances [for RT, $F(1,11)=95.8, p<.01$; for accuracy, $F(1,11)$ $=27.1, p<.01]$. The two-way interaction between compatibility and distance was also significant for both RT and accuracy [for RT, $F(1,11)=23.8, p<.01$; for accuracy, $F(1,11)=15.0, p<.01]$. The responsecompatibility effects decreased as the distractors were moved farther from the target. Thus far, the pattern of

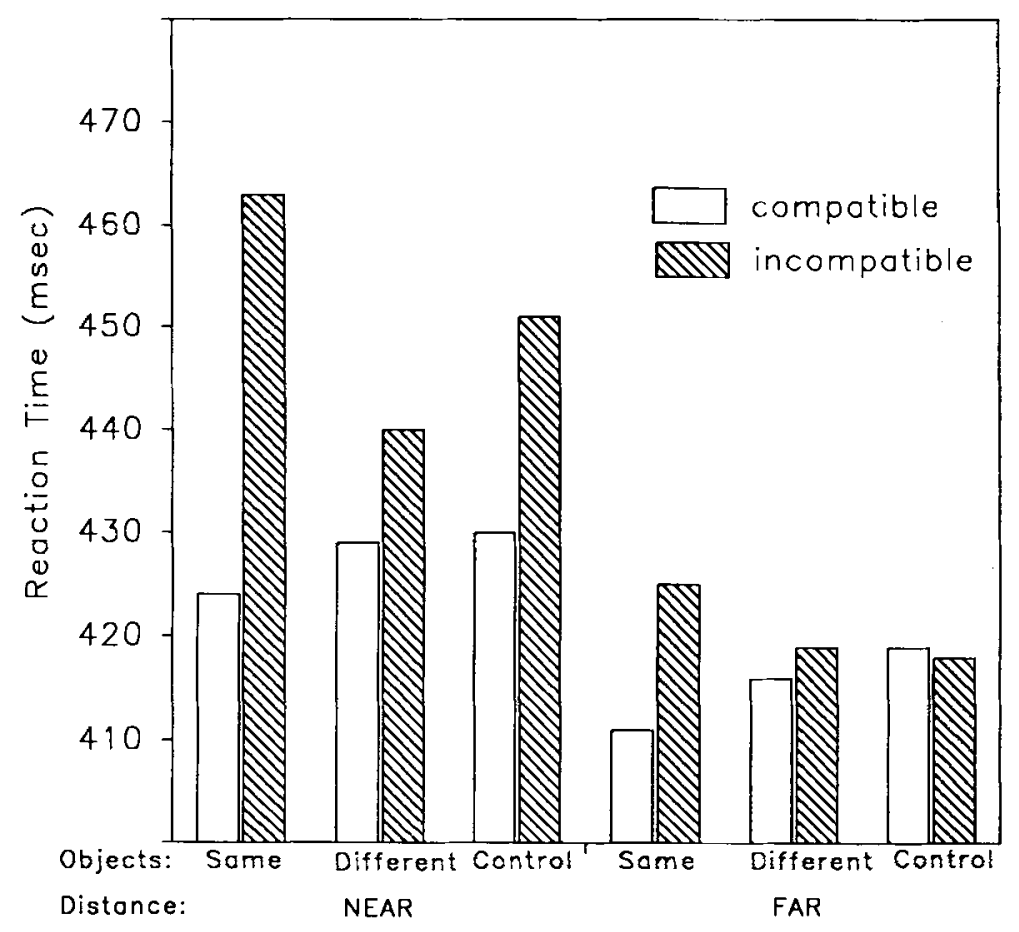

Figure 3. Average correct reaction times for each of the conditions in Experiment 2. 
Table 2

Mean Percent Correct Scores for Each of the Conditions in Experiment 2

\begin{tabular}{|c|c|c|c|c|c|c|}
\hline \multirow[b]{2}{*}{ Distance } & \multicolumn{3}{|c|}{ Response-Compatible } & \multicolumn{3}{|c|}{ Response-Incompatible } \\
\hline & $\begin{array}{c}\text { Same } \\
\text { Object }\end{array}$ & $\begin{array}{c}\text { Different } \\
\text { Object }\end{array}$ & Control & $\begin{array}{c}\text { Same } \\
\text { Object }\end{array}$ & $\begin{array}{c}\text { Different } \\
\text { Object }\end{array}$ & Control \\
\hline $\begin{array}{l}\text { Near } \\
\text { Far }\end{array}$ & $\begin{array}{l}95.3 \\
95.2\end{array}$ & $\begin{array}{l}93.2 \\
94.6\end{array}$ & $\begin{array}{l}94.0 \\
96.3\end{array}$ & $\begin{array}{l}89.5 \\
93.4\end{array}$ & $\begin{array}{l}92.1 \\
94.5\end{array}$ & 90.9 \\
\hline
\end{tabular}

results obtained in Experiment 2 was quite similar to that obtained when both contour and color were used to distinguish between same- and different-object conditions.

The similarity between Experiments 1 and 2 is further underscored by the significant two-way interactions between compatibility and object type [for RT, $F(2,22)=$ $6.9, p<.01$; for accuracy, $F(2,22)=25.6, p<.01]$. As can be seen in Figure 3, the response-compatibility effect was largest in the same-object condition $(26.5 \mathrm{msec})$, smaller in the MS control condition (10 msec), and smallest in the different-object condition $(7 \mathrm{msec})$. Table 2 reveals a similar pattern of effects for accuracy. The responsecompatibility effect decreased from the same-object (3.8\%), to the MS control $(1.7 \%)$, to the different-object condition (.6\%). Post hoc comparisons indicated that the differences between the response-compatible and responseincompatible conditions were significant for the same-object condition for RT and for the same-object and MS control conditions for accuracy $(p s<.05)$. Furthermore, the differences between the same- and different-object conditions can be attributed to increased RTs and decreased accuracies for the response-incompatible trials and increased accuracies for the response-compatible trials in the sameas opposed to the different-object condition $(p s<.05)$. The average RT and accuracy in the SS control condition were $416 \mathrm{msec}$ and $95.0 \%$, respectively.

The subjects' ratings of the number of groups in each display corresponded to those obtained when both contour and color were used to code object conditions. Three groups were selected in the same- and different-object displays. In the same-object condition, the neutral flankers formed two separate groups, while the target and near distractors were viewed as another group. In the differentobject condition, the near distractors and neutral flankers formed a group on each side of the display, while the target was viewed as a separate group. Five separate groups, one for each of the vertical lines, were indicated in the MS control condition. Each of the 12 subjects indicated the same grouping structure.

The strength of grouping ratings were subjected to a three-way repeated measures ANOVA (distance $\times$ compatibility $x$ object type). The mean strength rating across conditions was $6.1(1=$ weak grouping, $7=$ strong grouping). Only object type was significant $[F(2,22)=$ $118.2, p<.01]$. The same- $(6.3)$ and different-object (6.4) conditions were rated as more strongly grouped than the MS control condition (5.6). The cue-utilization data was also subjected to a repeated measures ANOVA. The mean use rating was 6.2. No main effects or interactions were significant. ${ }^{4}$

\section{Discussion}

The primary issue investigated in Experiment 2 was whether the pattern of performance effects and subjective ratings obtained when both contour and color cues were used to code object conditions would be obtained when color cues, and presumably the principle of similarity, were used alone. All of the major effects obtained in Experiment 1 were replicated in Experiment 2. First, the response-compatibility effect was significantly larger when the target and distractors were presented in the same color than when they were presented in different colors. Second, the response-compatibility effect varied in a graded fashion that was consistent with the subjects' ratings of grouping strength. The response-compatibility effect decreased from the same-object condition, to the MS control condition, to the different-object condition. Third, the magnitude of the response-compatibility effect decreased as separation between the target and distractors increased. Finally, some evidence was obtained which suggested that changes in the response-compatibility effect could be attributed to both improved performance on response-compatible trials and poorer performance on response-incompatible trials in the same- as opposed to the different-object condition.

Although the close correspondence between the results obtained in Experiment 2 and in Experiment 1 suggested that color coding could have an important influence on focused attention, the interpretation of the color effects remained to be determined. Earlier we suggested that changes in the response-compatibility effect as a function of color coding could be interpreted in terms of either changes in visual confusability across conditions or perceptual grouping. Given the findings in Experiment 2, we believe that the notion of perceptual grouping provides a more plausible interpretation than visual confusability. Our logic is as follows. A confusability interpretation would suggest that presenting the target and distractors in the same color would render the stimuli less discriminable than would be the case if they were presented in separate colors, thereby increasing RT and decreasing accuracy. This interpretation predicts the larger response-compatibility effect that was obtained in the same- as opposed to the different-color/object conditions.

However, two other aspects of the data are not predicted by the notion of confusability. First, an interpretation based 
on confusability would predict decreases in performance for both response-compatible and response-incompatible trials in the same- as opposed to the different-color condition, owing to the similarity of color codes for the response-compatible and response-incompatible trials in the same-color condition. Contrary to this prediction, performance actually improved for the response-compatible trials in the same-color condition. Second, confusability would predict similar response-compatibility effects in the same-object and MS control conditions, since the target and distractors are presented in the same color in both of these conditions. However, the response-compatibility effect was significantly larger in the same-object condition than in the MS control condition. Although these data may not rule out a more sophisticated version of the confusability hypothesis, in which confusability only varies for nonidentical targets and distractors that can be easily distinguished from their background, a simple notion of confusability is inadequate to explain our results.

\section{EXPERIMENT 3}

Our primary purpose in Experiment 3 was to determine whether the pattern of performance effects and subjective ratings obtained when color and contour or color alone coded object conditions would be obtained when contour, and presumably the principle of closure, alone coded object conditions. In Experiment 2, color was sufficient to produce object type $\times$ compatibility effects. Trials on which the target and the distractors were presented in the same color resulted in performance costs with responseincompatible distractors and performance benefits with response-compatible distractors, relative to trials on which the target and distractors were displayed in different colors. A comparison of the results obtained in Experiment 2 with those obtained in Experiment 3 would indicate whether contour was sufficient to produce the performance effects. If the object type $\times$ compatibility effect was not obtained when the principle of closure was applied in the absence of similarity coding, our interpretation of the changes in the response-compatibility effect in terms of perceptual grouping would be considerably weakened.

\section{Method}

Subjects. Twelve right-handed subjects, 4 males and 8 females, participated in the study. Their ages ranged from 18 to 22 . All had normal or corrected-to-normal vision. They were paid $\$ 4.50$ per hour for their participation.

Stimuli and Apparatus. The stimuli were identical to those in Experiment 1 (see Figure 1), with the exception that the object conditions were represented by contour (e.g., the addition of the horizontal lines) but not color. All stimuli were white lines drawn on a black background. In the same-object condition, the target was attached to the distractors by horizontal lines. In the different-object condition, the distractors were connected to the neutral flankers by the horizontal lines. In the MS control condition, horizontal lines were not included in the display.

Procedure. The procedure was equivalent to that in Experiments 1 and 2.
Experimental design. A within-subjects three-way factorial was used. The factors included compatibility (response-compatible and response-incompatible distractors), distance (near and far), and object type (MS control, same and different objects). Contour was used to code the same- and different-object conditions. In the control condition, horizontal lines were not used to interconnect the vertical lines. The order of trials was randomized within each block.

\section{Results}

The mean correct RT and percent correct scores are presented in Figure 4 and Table 3, respectively. The RTs and accuracies were subjected to three-way repeated measures ANOVAs (distance $\times$ compatibility $\times$ object type). Main effects were obtained for both compatibility [for RT, $F(1,11)=26.6, p<.01$; for accuracy, $F(1,11)=6.7$, $p<.05$ ] and distance [for RT, $F(1,11)=46.9, p<.01$; for accuracy, $F(1,11)=13.3, p<.011$. Targets that were surrounded by response-incompatible distractors resulted in longer RTs and lower accuracies than did targets that were surrounded by response-compatible distractors. RTs decreased and accuracies increased when the distractors were moved from the $.25^{\circ}$ to the $1.0^{\circ}$ locations. The two-way interaction between compatibility and distance was also significant [for RT, $F(1,11)=28.7, p<.01$; for accuracy, $F(1,11)=62.1, p<.01]$. The responsecompatibility effect decreased from the near to the far flanker locations.

More important, however, was the significant two-way interaction between object type and compatibility [for RT, $F(2,22)=14.1, p<.01 ;$ for accuracy, $F(2,22)=22.4$, $p<.01$ ]. As can be seen from Figure 4, the responsecompatibility effect was largest in the same-object condition (26 msec), substantially smaller in the MS control condition $(8.5 \mathrm{msec})$, and smallest in the different-object condition $(2 \mathrm{msec})$. Table 3 reveals a similar pattern of results for the accuracy measure. The response-compatibility effect decreased from the same-object $(5.0 \%)$, to the MS control (1.6\%), to the different-object condition (.5\%). Post hoc comparisons indicated that the differences between the response-compatible and response-incompatible conditions were significant for the same-object and MS control conditions for RT and for the same-object condition for accuracy $(p s<.05)$. Furthermore, the difference between the same- and different-object conditions can be attributed to increased RTs and decreased accuracies for the response-incompatible trials and decreased RTs and increased accuracies for the response-compatible trials in the same- as opposed to the different-object condition ( $p s<.05)$. The average RT and accuracy for the SS control condition were $408 \mathrm{msec}$ and $95.5 \%$, respectively.

The subjects' ratings of the number of groups in each display corresponded to those obtained when color and contour or just color coded different objects. Three groups were selected in the same- and different-object displays. In the same-object condition, the neutral flankers formed two separate groups, while the target, near distractors, and horizontal lines were viewed as another group. In the different-object condition, the near distractors, horizon- 


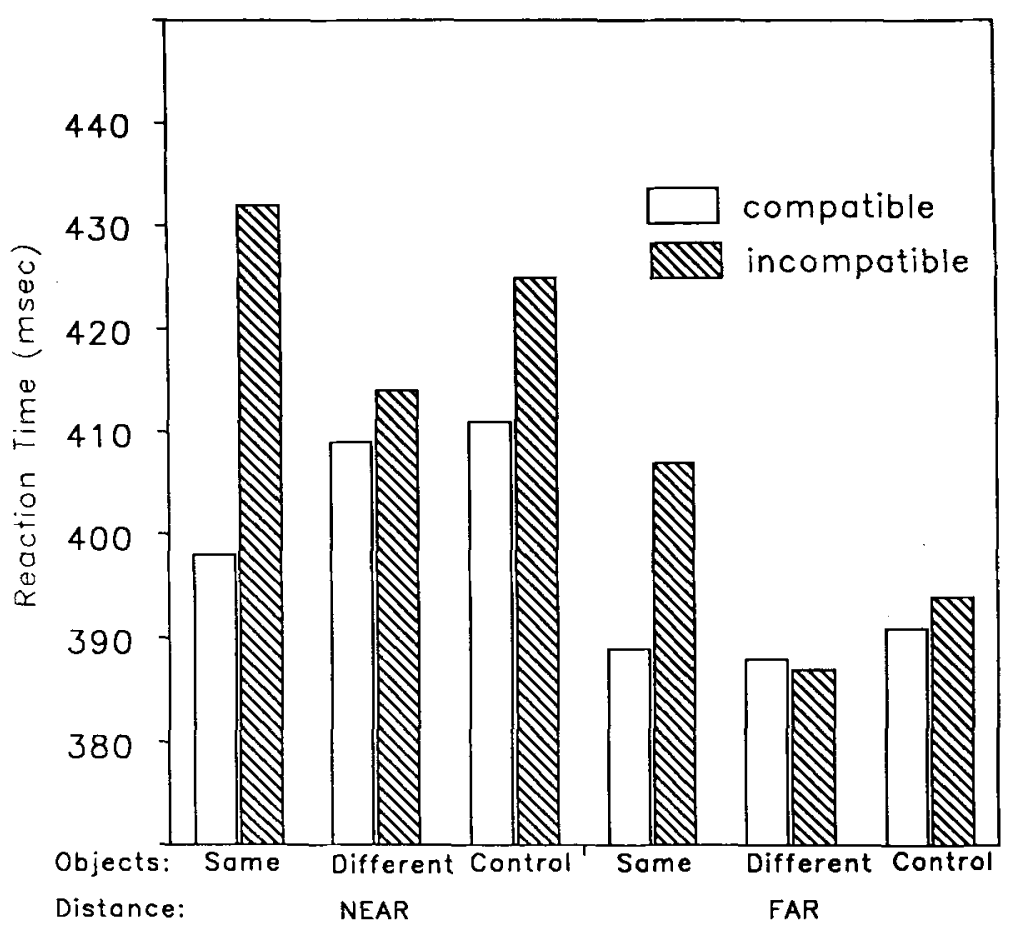

Figure 4. Average correct reaction times for each of the conditions in Experiment 3.

tal lines, and neutral flankers formed a group on each side of the display, while the target was viewed as a separate group. Five separate groups, one for each of the vertical lines, were indicated in the MS control condition. Each of the subjects indicated the same grouping structure.

The strength-of-grouping ratings were subjected to a three-way repeated measures ANOVA (distance $\times$ compatibility $\times$ object type). The mean strength rating across conditions was $5.8(1=$ weak grouping, $7=$ strong grouping). Only the object-type main effect was significant $[F(1,11)=27.3, p<.01]$. The same- $(5.9)$ and different-object (6.1) conditions were rated as more strongly grouped than the MS control condition (5.1). The cue-utilization data was also subjected to a repeated measures ANOVA. The mean rating was 5.6. No main effects or interactions attained statistical significance.

A comparison of the RT and accuracy data across Experiments 1,2 , and 3 suggests that (1) the grouping effects were quite similar regardless of whether contour or color was used to code different objects and (2) the single cues used in Experiments 2 and 3 produced a pattern of results much like that obtained when multiple cues were used to code different objects in Experiment 1. In an effort to quantify these observations, ANOVAs were conducted to compare performance with the redundant contour and color cues (Experiment 1) with performance with the color cues (Experiment 2) and the contour cues (Experiment 3).

No significant main effects or interactions of the experiment factor were obtained in the analysis of accuracy. Only the main effect of experiment was significant for RT $[F(2,66)=18.2, p<.01]$. RTs were significantly faster when contour was used to code different objects (Experiment 3) than when contour and color (Experiment 1) or color (Experiment 2) constituted the cue. Overall, these analyses suggest that the pattern of effects-in particular the interaction of response compatibility with object type-obtained with redundant coding was the same as that obtained in the single-cue conditions.

\section{Discussion}

The results of Experiment 3 replicate the pattern of effects found in Experiments 1 and 2. Thus, it appears that the influence of the object/grouping manipulation on the

Table 3

Mean Percent Correct Scores for Each of the Conditions in Experiment 3

\begin{tabular}{|c|c|c|c|c|c|c|}
\hline \multirow[b]{2}{*}{ Distance } & \multicolumn{3}{|c|}{ Response-Compatible } & \multicolumn{3}{|c|}{ Response-Incompatible } \\
\hline & $\begin{array}{l}\text { Same } \\
\text { Object }\end{array}$ & $\begin{array}{c}\text { Different } \\
\text { Object }\end{array}$ & Control & $\begin{array}{l}\text { Same } \\
\text { Object }\end{array}$ & $\begin{array}{c}\text { Different } \\
\text { Object }\end{array}$ & Control \\
\hline $\begin{array}{l}\text { Near } \\
\text { Far }\end{array}$ & $\begin{array}{l}96.8 \\
95.6\end{array}$ & $\begin{array}{l}93.6 \\
95.2\end{array}$ & $\begin{array}{l}94.1 \\
94.9\end{array}$ & $\begin{array}{l}88.3 \\
94.1\end{array}$ & $\begin{array}{l}92.8 \\
95.0\end{array}$ & $\begin{array}{l}91.4 \\
94.5\end{array}$ \\
\hline
\end{tabular}


response-compatibility effect does not depend on whether the objects are coded by contour, color, or both contour and color. The correspondence of the results across experiments further suggests that the principles of similarity and closure influenced focused attention performance in a similar fashion, through the preattentive grouping of items in the visual field. However, it is also important to note that a third principle of grouping-proximity-exerted a considerable influence on performance. In each of the experiments, the response-compatibility effect decreased from the near to the far target-distractor separations. Given that this effect could not be attributed to changes in acuity, it appears that three grouping principles were responsible for the changes in the magnitude of the response-compatibility effect across conditions.

\section{GENERAL DISCUSSION}

Our main objective in the present series of experiments was to investigate the influence of Gestalt grouping principles on the size of the response-compatibility effect in a focused attention paradigm. More specifically, we were interested in examining these effects within the framework of object-based and space-based models of visual attention. In order to contrast these classes of models, we controlled the proximity between the target and distractors and varied the object relations. Targets and distractors were embedded within the same object, presented in the same color, or presented in different objects or colors.

Space-based models predict that RTs should be longer and accuracies lower when response-incompatible flankers are located in close proximity to the target (Broadbent, 1982; Downing \& Pinker, 1985; B. A. Eriksen \& C. W. Eriksen, 1974; C. W. Eriksen \& St. James, 1986; Jonides, 1983; Posner et al., 1980). The object manipulations should have no influence on performance, since they do not modify the distance between the target and the distractors. In contrast, object-based models predict that the disruptive effect of response-incompatible distractors can be reduced by locating these stimuli on objects different from the target, even if the target and distractors remain in close physical proximity (Duncan, 1984; Duncan \& Humphreys, 1989; Kahneman \& Henik, 1977; Kramer et al., 1985; Neisser, 1967; Treisman et al., 1983).

The results of these three experiments provide some support for both the object- and the space-based models of attention. The response-compatibility effect was either drastically reduced or eliminated when distractors and targets were presented on different objects or in different colors, suggesting that even despite the close physical proximity of the target and distractors, subjects were capable of focusing on the target object and excluding the distractor objects. Furthermore, RTs were faster and accuracies were higher when response-compatible distractors and the target were embedded in the same object than when they were located on separate objects. Conversely, RTs increased and accuracies decreased when response-incompatible distrac- tors and the target were embedded in the same object rather than on separate objects. Thus, it appears that the object relations enhanced both facilitation and interference effects, depending on the relationship between the target and the distractors.

There are, however, at least two difficulties in the data for object-based models of attention. The first concerns the decreased response-compatibility effect for the sameobject condition when the distractors are moved from the $.25^{\circ}$ to the $1^{\circ}$ separation. As described earlier, objectbased models predict costs and benefits in performance on the basis of whether or not the target and the distractors are located on the same object, independently of the separation of the task-relevant attributes of the object. Of course, there are limits to this argument, given changes in acuity with retinal eccentricity. In the present case, however, the results from a pilot study (see the discussion of Experiment 1) suggest small and nonsignificant changes in discriminability of the stimuli when the near and far locations were compared in a choice reaction time task. A second difficulty for object-based models concerns the nature of the grouping effects. In each of the experiments, the response-compatibility effects were largest in the same-object condition, of intermediate size in the MS control condition, and smallest in the different-object condition. Object-based models, on the other hand, suggest that the magnitude of the response-compatibility effect should be the same in the MS control and different-object conditions, since in each of these conditions the distractors were perceived as distinct from the target.

Although it is clear that neither class of models provides a complete account of our data, an important question concerns how individual space- and object-based models might accommodate our findings. We will begin by discussing the three different types of space-based models. Spotlight models have several important properties. First, spotlights are considered to be unitary in nature (Broadbent, 1982; Posner et al., 1980). Thus, attention cannot be simultaneously allocated to noncontiguous areas of the visual field. Second, the processing of different elements in the visual field usually necessitates the movement of the spotlight (Posner, 1980; Remington \& Pierce, 1984; Shulman, Wilson, \& Sheehy, 1985). Finally, spotlights are assumed to be of limited spatial extent (Broadbent, 1982; LaBerge, 1983; Posner, 1980). Given these characteristics, it is obvious that spotlight models can account for the effects of target/distractor separation on performance. A small response-compatibility effect would be expected if the distractors fell outside of the attentional spotlight.

On the other hand, changes in the magnitude of the response-compatibility effect with variations in contour and color coding are more difficult for the spotlight model to explain. If we assume that the self-paced nature of our task, along with the 200-msec fixation cue, would enable subjects to orient the spotlight to the target location prior to the appearance of the stimulus array, then why should the color and contour coding influence the response-compatibility 
effect? One possibility that we have previously entertained is that color coding may modify the degree of confusability between the target and the distractors. Thus, presentation of the target and distractors in the same color may render them more confusable, relative to their being presented in different colors. Such an explanation would be consistent with the spotlight model, were we to assume that processing time increases as the confusability of the target and distractors increases. However, this interpretation appears unlikely, given that (1) the same pattern of responsecompatibility effects was found when contour was changed, which did not involve the direct modification of the target and distractors, and (2) response-compatible trials in which the distractors and target were coded in the same color resulted in better performance than did responsecompatible trials in which the target and distractors were presented in different colors.

A possible solution to this dilemma would be for the spotlight theorists to adopt the position taken by Treisman and her colleagues (Treisman \& Gelade, 1980; Treisman \& Gormican, 1988; Treisman \& Sato, 1990; see also Duncan \& Humphreys, 1989; Wolfe et al., 1989) that the attentional spotlight is, under certain conditions, guided by a preattentive segmentation of the visual field. Although Treisman and her coworkers have confined their investigation of grouping processes to visual search paradigms, it is plausible that the same two-step process (i.e., preattentive analysis of the visual field followed by focal attention) may function in focused attention tasks, given the availability of grouping cues. It is important to note, however, that such a modification of the traditional spotlight model changes the emphasis on space's being a primary cue for attentional guidance to its being one of a subset of cues, at least in the initial analysis of the visual scene (as in Neisser, 1967).

The second type of space-based model that we will discuss has been referred to as the gradient model. It is important, however, to distinguish between two versions of this model. In the static version, the gradient in twodimensional space has been proposed to fall off from the focus of attention according to a negatively accelerating function defined over visual angle separation (Downing \& Pinker, 1985). Given its static nature, it seems unlikely that this model could be easily modified, short of modifying it to respond in a dynamic fashion to structural changes in the display, to account for changes in the responsecompatibility effect as a function of the color/contour manipulations. On the other hand, dynamic versions of the gradient model have been proposed to accommodate recent findings which suggest that, depending on subject strategies and task demands, efficient processing can occur over either a narrow or a wide area of visual space (Downing, 1988; LaBerge \& Brown, 1986). One such model has been proposed by LaBerge and Brown (1989) to predict attentional operations in shape identification. An important component of this model is the location expectation module, which is responsible for establishing an attentional gradient centered on the expected location of a target. Furthermore, the shape of the gradient can be modified by the output of another module, the position analyzer, on the basis of the similarity of the target and distractors. High target-distractor similarity leads to the establishment of a narrow gradient in an effort to filter out the distractors.

It would appear that the LaBerge and Brown (1989) model may be capable of accounting for a subset of our results, given the assumption that color coding modifies the confusability between the target and distractors. However, as argued above, the confusability interpretation falls short in predicting (1) better performance for the samecolor response-compatible trials than for the differentcolor response-compatible trials, (2) performance in the contour-coding experiment, and (3) differences in performance between the MS control condition and the sameand different-object conditions. However, if the position analyzer module were modified to provide input concerning perceptual grouping in general, rather than similarity in particular, the gradient could be adjusted, in a bottomup or stimulus-driven fashion, to accommodate our results. In this case, the gradient could be adjusted on the basis of a metric of grouping strength, thereby producing a graded pattern of response-compatibility effects. Although this type of modification certainly complicates the application of the model, the added complexity may be offset by the ability to predict a wider variety of attentional effects.

Finally, the third type of space-based model that we will discuss has been labeled the zoom-lens model (C. W. Eriksen \& St. James, 1986; C. W. Eriksen \& Yeh, 1985). In this model, attention can be dynamically allocated along a continuum from tightly focused to widely distributed. However, as with a zoom lens, the resolving power of the attentional beam is an inverse function of its width. A series of studies conducted by C. W. Eriksen and his colleagues (C. W. Eriksen \& Colegate, 1971; C. W. Eriksen \& Rohrbaugh, 1970) have suggested that attention can be concentrated at a specific location in a display by a precue as short as $50 \mathrm{msec}$ prior to stimulus onset. On the other hand, with the absence of a location precue, or with more than $33 \%$ of the potential target positions precued, it appears that attention is distributed across the display (C. W. Eriksen \& St. James, 1986). If the subjects in our experiments had sufficient time to restrict their attention to the target location, then within the zoom-lens model the variations in the responsecompatibility effect as a function of color/contour coding must be due to either the movement of a tightly focused beam of attention to inspect the distractors or the expansion of the narrow focus to encompass the distractors in some of the conditions. The former hypothesis appears unlikely, since C. W. Eriksen and Yeh (1985) have estimated that the movement of a tightly focused attentional beam takes approximately $70 \mathrm{msec}$. None of our response-compatibility effects exceeded $40 \mathrm{msec}$. On the other hand, it is plausible that the width of the focus might expand to accommodate the distractors in some of the con- 
ditions. Thus, similar to our proposal for the gradient models, the width of the zoom lens might vary in response to a preliminary analysis of the structural aspects of the display. In the present case, the attentional beam could have expanded to encompass the perceptual group(s) that included the target.

Two different varieties of grouping or object-based models can also be distinguished. In the first type, which we have referred to as the object-based model, attention is directed to preattentively defined perceptual objects. Furthermore, attending to an object results in the mandatory processing of all properties of that object (Duncan, 1984; Kahneman \& Henik, 1981; Kahneman et al., 1983; Kahneman \& Treisman, 1984). As we have stated, this model provides a good account of (1) the larger response-compatibility effect in the same- as opposed to the different-object condition and (2) improved performance for response-compatible trials and poorer performance for response-incompatible trials in the same-as opposed to the different-object condition. On the other hand, the objectbased model has more difficulty in accounting for the graded influence of grouping on the response-compatibility effect and the decreased response-compatibility effect in the same-object condition as separation between the target and distractors increases.

One way for this model to accommodate the graded grouping effect would be for it to incorporate the hierarchical nature of objects or perceptual groups (Duncan, 1984). Most real-world structures are composed of objects at a number of different levels of scale. For example, a building might be considered an "object" composed of other objects such as floors or wings, which in turn are composed of objects such as windows and doors. Our intuition, which is corroborated by the large literature on global/local processing (see, e.g., Hoffman, 1980; Kinchla, Solis-Macias, \& Hoffman, 1983; Kinchla \& Wolfe, 1979; Navon, 1977; Pomerantz, 1981) is that we can selectively focus on different levels of hierarchically arranged objects.

In the present experiments, the contour and color coding in the same- and different-object conditions might provide simpler and more spatially restricted objects on which to focus, thereby increasing or decreasing the size of the response-compatibility effect relative to the MS control condition. Thus, the same- and different-object conditions might encourage the processing of a lower level object, whereas a higher level object might be processed in the MS control condition. This hierarchical organization hypothesis requires two assumptions. First, the MS control condition must be considered as a single, albeit higher order, object in relation to the objects perceived in the same- and different-object conditions. At first glance, the subjective ratings of the number of groups in each display would seem to belie this assumption, since the subjects indicated five objects or groups in the MS control condition and three groups in same- and different-object conditions. However, the number of groups perceived in each display may have been strongly dependent on the way that we asked the question about grouping. We asked subjects to indicate each of the objects or groups in a display. Thus, this question may have suggested that there were several objects in a display. If, on the other hand, we had asked subjects to rate on a 1-7 scale $(1=$ items do not form a good group; $7=$ items form a good group) whether the items in the display could be considered to form a single group, the lack of distinguishing color and contour in the MS control condition might have resulted in higher grouping ratings than would have been obtained in the same- and different-object conditions. We tried this revised question with 6 new subjects and found that indeed the ratings of a unitary group were significantly higher for the MS control conditions (4.1) than they were for the same- $(1.8)$ or different-object (1.7) conditions.

A second assumption in the hierarchical organization hypothesis is that the components of lower level objects are processed more intensively than the components of higher level objects. This presupposes a limited attentional capacity that can be used to process many properties or components of a higher level object at a reduced efficiency, or fewer components of a lower level object at a higher efficiency per component. Thus, in the present experiments, the size of the response-compatibility effect may have been due, in part, to the level of the object that was processed in each of the displays. In the same-object conditions, the response-compatibility effect would have been large due to the intensive processing of the distractors located on the (lower level) target object. On the other hand, the restricted focus on the target object in the different-object condition would have resulted in minimal distractor processing. Finally, the response-compatibility effect would have been of intermediate size in the MS control condition, because of the less intensive processing of the distractors in this higher level object.

The second difficulty for the object-based model, the decrease in the response-compatibility effect that accompanies increased target/distractor separation, might also be resolved within the framework of the hierarchical organization hypothesis. Thus far, we have argued that processing capacity or attention is limited and must be allocated among the properties of an object. Therefore, less processing capacity would be available for a property of a higher level object than for the same property of a lower level object. The decreased response-compatibility effect that accompanied increased target-distractor separation could be accommodated by extending the processing capacity claim to physical space. Thus, if processing capacity was divided among object properties as well as the space in which the properties were located, a reduced response-compatibility effect would be expected for the wider target/distractor separation, because of the availability of fewer resources for the processing of the distractors at a larger separation.

The second type of grouping or object-based model that we will discuss has been referred to as the groupingstrength model (Duncan, 1984). This model can be considered a synthesis of research and theorizing about the 
influence of Gestalt grouping principles on visual attention (Banks \& Prinzmetal, 1976; Beck, 1982; Fryklund, 1975; Harms \& Bundesen, 1983; Pomerantz \& Schwaitzberg, 1975; Prinzmetal \& Banks, 1977). The groupingstrength model is similar to the object-based model in its endorsement of the two-step process of a preattentive segmentation of the visual field followed by a more intensive analysis of a limited number of groups or perceptual units. However, the two models differ in how they characterize the output of the segmentation process. In the objectbased model, the output is treated as a set of discrete groups of objects, whereas in the grouping-strength model, the output is treated in terms of elements organized along a continuum of grouping strength. Thus, within the grouping-strength model, all groups are not created equal; instead, they vary in the degree to which their elements cohere.

The grouping-strength model appears to be capable of accounting for most of our major findings. For example, the graded response-compatibility effect could be interpreted in terms of the strength of grouping of the distractors with the target and neutral flankers. In the same-object conditions, the distractors were presented in the same color as was the target, and they were also connected to the target by horizontal lines. Thus, on the basis of Gestalt principles of similarity and closure, the distractors would be strongly grouped with the target and weakly grouped with the neutral flankers (e.g., because of the lack of common contour and color). Conversely, an application of the same principles would suggest that in the differentobject conditions, the distractors would be strongly grouped with the neutral flankers, owing to common contour and color, and weakly grouped with the target. Finally, in the MS control condition, the strength of grouping between the distractors and target and between the distractors and neutral flankers would be predicted to be equivalent because of the lack of contour and distinguishing color.

Within the grouping-strength model, the decreased response-compatibility effect that resulted from increasing the separation between the target and distractors could be interpreted within the context of the principle of proximity. Previous research has suggested that grouping strength decreases as the proximity between different elements increases (Pomerantz \& Schwaitzberg, 1975). In the present case, the decreased grouping strength at the far separation would be expected to result in a decreased interference or facilitation from the distractors.

In conclusion, we believe that our analysis of the results of the three experiments within the context of a variety of space-based and object-based models suggests several important implications for our understanding of the mechanisms underlying the control of visual attention. First, neither the space-based nor the object-based models provide a complete and unambiguous account of our findings. It would appear that both space and grouping principles such as similarity and closure play an important role in visual attention. Thus, although each of the three space-based models-spotlight, gradient, and zoom lens- can be modified to accommodate the effects of color and contour on the magnitude of the response-compatibility effect, our analyses suggest the need for a structural analysis of the display in addition to a process that restricts attention to a portion of the visual field. Second, the grouping-strength model appears to provide a more parsimonious account of our results than the object-based model does. However, the appearance of parsimony depends on the existence of an a priori method of describing the strength of grouping across a wide variety of displays. Although there have been some efforts in this direction (Banks \& Prinzmetal, 1976; Prytulak, 1974), it appears that at present both the object-based model and the grouping model provide plausible alternative accounts of the control of visual attention.

\section{REFERENCES}

ANDERSEN, G. J. (1990). Focused attention in three-dimensional space. Perception \& Psychophysics, 47, 112-120.

ANSTIS, S. M. (1974). A chart demonstrating variations in acuity with retinal position. Vision Research, 14, 589-592.

Banks, W. P., Bodinger, D., Illige, M. (1974). Visual detection accuracy and target-noise proximity. Bulletin of the Psychonomic Society, 2, 411-414.

Banks, W. P., Prinzmetal, W. (1976). Configurational effects in visual information processing. Perception \& Psychophysics, 19, 361-367.

BASHINSKI, H. S., BACHARACH, V. R. (1980). Enhancement of perceptual sensitivity as the result of selectively attending to spatial locations. Perception \& Psychophysics, 28, 241-248.

BECK, J. (1982). Textural segregation. In J. Beck (Ed.), Organization and representation in perception (pp. 285-317). Hillsdale, NJ: Erlbaum.

BECK, J., \& AMBLER, B. (1973). The effects of concentrated and distributed attention on peripheral acuity. Perception \& Psychophysics, 14, 225-230.

Broadbent, D. (1982). Task combination and selective intake of information. Acta Psychologica, 50, 253-290.

Bundesen, C., Pedersen, L. F. (1983). Color segregation and visual search. Perception \& Psychophysics, 33, 487-493.

DownING, C. J. (1988). Expectancy and visual-spatial attention: Effects on perceptual quality. Journal of Experimental Psychology: $\mathrm{Hu}$ man Perception \& Performance, 14, 188-202.

Downing, C. J., PINker, S. (1985). The spatial structure of visual attention. In M. I. Posner \& O. Marin (Eds.), Attention and performance $X I$ (pp. 171-187). Hillsdale, NJ: Erlbaum.

Driver, J., BAYLIS, G. C. (1989). Movement and visual attention: The spotlight metaphor breaks down. Journal of Experimental Psychology: Human Perception \& Performance, 15, 448-456.

DunCAN, J. (1984). Selective attention and the organization of visual information. Joumal of Experimental Psychology: General, 113, 501-517.

Duncan, J., \&umphreys, G. W. (1989). Visual search and stimulus similarity. Psychological Review, 96, 433-458.

Egeth, H. E., Virzi, R. A., \& Garbart, H. (1984). Searching for conjunctively defined targets. Joumal of Experimental Psychology: Human Perception \& Performance, 10, 32-39.

Eriksen, B. A., \& Eriksen, C. W. (1974). Effects of noise letters upon the identification of a target letter in a nonsearch task. Perception \& Psychophysics, 16, 143-149.

Eriksen, C. W., Colegate, R. L. (1971). Selective attention and serial processing in briefly presented visual displays. Perception \& Psychophysics, 10, 321-326.

Eriksen, C. W., \& Hoffman, J. E. (1972). Temporal and spatial characteristics of selective encoding from visual displays. Perception \& Psychophysics, 12, 201-204.

Eriksen, C. W., \& Hofrman, J. E. (1973). The extent of processing 
noise elements during selective encoding from visual displays. Perception \& Psychophysics, 14, 155-160.

ErIKSEN, C. W., Rohrbaugh, J. W. (1970). Some factors determining efficiency of selective attention. American Journal of Psychology, 83, 330-342.

ERIKSEN, C. W., \& SchUltz, D. W. (1979). Information processing in visual search: A continuous flow conception and experimental results. Perception \& Psychophysics, 25, 249-263.

ERIKSEN, C. W., \& ST. JAMES, J. D. (1986). Visual attention within and around the field of focal attention: A zoom lens model. Perception \& Psychophysics, 40, 225-240.

ERIKSEN, C. W., \& YeH, Y.-Y. (1985). Allocation of attention in the visual field. Joumal of Experimental Psychology: Human Perception \& Performance, 11, 583-597.

Falmagne, J. C. (1968). Note on a simple fixed point property of binary mixtures. British Journal of Mathematical and Statistical Psychology, 21, 131-132

Flowers, J. H., \& WiLcox, N. (1982). The effect of flanking context on visual classification: The joint contribution of interactions at different processing levels. Perception \& Psychophysics, 32, 581-591.

FRYKLUND, I. (1975). Effects of cued-set spatial arrangement and targetbackground similarity in the partial-report paradigm. Perception \& Psychophysics, 17, 375-386.

GARNER, W. R. (1987). Location and color as cuing dimensions in contingent classification. Perception \& Psychophysics, 41, 202-210.

GatTI, S. V., EGETH, H. E. (1978). Failure of spatial selectivity in vision. Bulletin of the Psychonomic Society, 11, 181-184.

Grice, G. R., \& GWYNNE, J. W. (1985). Temporal characteristics of noise conditions producing facilitation and interference. Perception \& Psychophysics, 37, 495-501.

HARMS, L., BUNDESEN, C. (1983). Color segregation and selective attention in a nonsearch task. Perception \& Psychophysics, 33, 11-19.

HofFMAN, J. E. (1980). Interaction between global and local levels of a form. Journal of Experimental Psychology: Human Perception \& Performance, 6, 222-234.

Hoffman, J. E., Houck, M. R., McMillan, F. W., Simons, R. F., a OAtman, L. C. (1985). Event related potentials elicited by automatic targets: A dual task analysis. Joumal of Experimental Psychology: Human Perception \& Performance, 11, 50-61.

Hoffman, J. E., Nelson, B. (1981). Spatial selectivity in visual search. Perception \& Psychophysics, 30, 283-290.

HuGHEs, H. C., ZIMBA, L. D. (1985). Spatial maps of directed visual attention. Journal of Experimental Psychology: Human Perception \& Performance, 11, 409-430.

Humphreys, G. W. (1981). Flexibility of attention between stimulus dimensions. Perception \& Psychophysics, 30, 291-302.

Ishihari Color Blindness Test (1989). Tokyo: Kanehara.

JONIDES, J. (1983). Further toward a model of the mind's eye's movement. Bulletin of the Psychonomic Society, 21, 247-250.

Jonides, J., MACK, R. (1984). On the cost and benefit of cost and benefit. Psychological Bulletin, 96, 29-44.

Kahneman, D., Henik, A. (1977). Effects of visual grouping on immediate recall and selective attention. In S. Dornic (Ed.), Attention and performance VII (pp. 307-332). Hillsdale, NJ: Erlbaum.

Kahneman, D., Henik, A. (1981). Perceptual organization and attention. In M. Kubovy \& J. R. Pomerantz (Eds.), Perceptual organization (pp. 181-211). Hillsdale, NJ: Erlbaum.

Kahneman, D., Treisman, A. (1984). Changing views of attention and automaticity. In R. Parasuraman \& R. Davies (Eds.), Varieties of attention (pp. 29-62). New York: Academic Press.

Kahneman, D., Treisman, A., \& Burkell, J. (1983). The cost of visual filtering. Joumal of Experimental Psychology: Human Perception \& Performance, 9, 510-522.

Kinchla, R. A., Solis-Macias, V., \& Hoffman, J. (1983). Attending to different levels of structure in a visual image. Perception \& Psychophysics, 33, 1-10.

KINCHLA, R. A., \& WolfE, J. M. (1979). The order of visual processing: "Top-down," "bottom-up," or "middle-out." Perception \& Psychophysics, 25, 225-231.

Kramer, A. F., Wickens, C. D., \& Donchin, E. (1985). Processing of stimulus properties: Evidence for dual-task integrality. Journal of
Experimental Psychology: Human Perception \& Performance, 11, 393-408.

LABERGE, D. (1983). Spatial extent of attention to letters in words. Journal of Experimental Psychology: Human Perception \& Performance, 9, 371-379.

LABerge, D., \& Brown, V. (1986). Variations in size of the visual field in which targets are presented: An attentional range effect. Perception \& Psychophysics, 40, 188-200.

LABERGE, D., \& Brown, V. (1989). Theory of operations in shape identification. Psychological Review, 96, 101-124.

LAPPIN, J. (1967). Attention in the identification of stimuli in complex visual displays. Journal of Experimental Psychology, 75, 321-328.

LuDVIGH, E. (1941). Extrafoveal visual acuity as measured with Snellen test-letters. American Journal of Ophthalmology, 24, 303-310.

Mangun, G. R. R., \& Hillyard, S. A. (1987). The spatial allocation of visual attention as indexed by event-related brain potentials. $\mathrm{Hu}$ man Factors, 29, 195-211.

NAvon, D. (1977). Forest before trees: The precedence of global features in visual perception. Cognitive Psychology, 9, 353-383.

Neisser, U. (1967). Cognitive Psychology. Englewood Cliffs, NJ: Prentice Hall

Neisser, U., \& Becklen, R. (1975). Selective looking and attending to visually specified events. Cognitive Psychology, 7, 480-494.

O'Hara, W. P. (1980). Evidence in support of word unitization. Perception \& Psychophysics, 27, 390-402.

OHARA, W. [P]., \& ERIKSEN, C. W. (1979). Word unitization examined using an interference paradigm. Bulletin of the Psychonomic Society, 14, 81-84.

Podgorny, P., \& Shepard, R. (1983). The distribution of visual attention over space. Journal of Experimental Psychology: Human Perception \& Performance, 9, 380-393

Pomerantz, J. R. (1981). Perceptual organization in information processing. In M. Kubovy \& J. R. Pomerantz (Eds.), Perceptual organization (pp. 141-180). Hillsdale, NJ: Erlbaum.

Pomerantz, J. R., \& Pristach, E. A. (1989). Emergent features, attention, and perceptual glue in visual form perception. Joumal of $E_{x}$ perimental Psychology: Human Perception \& Performance, 4, 635-649.

Pomerantz, J. R., \& SChwaitzberg, S. D. (1975). Grouping by proximity: Selective attention measures. Perception \& Psychophysics, 18, 355-361.

PosNer, M. I. (1980). Orienting of attention. Quarterly Journal of Experimental Psychology, 32, 3-25.

Posner, M. I., Snyder, C. R. R. \& DAvidson, B. J. (1980). Attention and the detection of signals. Journal of Experimental Psychology: General, 109, 160-174.

Prinzmetal, W., Banks, W. P. (1977). Good continuation affects visual detection. Perception \& Psychophysics, 21, 389-395.

Prytulak, L. S. (1974). Good continuation revisited. Journal of Experimental Psychology, 102, 773-777.

Remington, R. [W]. \& PIERCE, L. (1984). Moving attention: Evidence for time-invariant shifts of visual selective attention. Perception \& Psychophysics, 35, 393-399.

Rock, I., \& GutTMaN, D. (1981). The effect of inattention on form perception. Journal of Experimental Psychology: Human Perception \& Performance, 7, 275-285.

Shulman, G. L., Remington, R. W., \& Mclean, J. P. (1979). Moving attention through visual space. Journal of Experimental Psychology: Human Perception \& Performance, 5, 522-526.

Shulman, G. L., Wilson, J., \& SheEhy, J. B. (1985). Spatial determinants of the distribution of attention. Perception \& Psychophysics, 37, 59-65.

TipPer, S. P., Brehaut, J. C., \& Driver, J. (1990). Selection of moving and static objects for the control of spatially directed attention. Journal of Experimental Psychology: Human Perception \& Performance, 16, 492-504.

Treisman, A. M., \& Gelade, G. (1980). A feature-integration theory of attention. Cognitive Psychology, 12, 97-136.

Treisman, A. M., Gormican, S. (1988). Feature analysis in early vision: Evidence from search asymmetries. Psychological Review, 95, 15-48. 
Treisman, A., Kahneman, D., Burkell, J. (1983). Perceptual objects and the cost of filtering. Perception \& Psychophysics, 33, 527-532.

Treisman, A., Sato, S. (1990). Conjunction search revisited. Journal of Experimental Psychology: Human Perception \& Performance, 16, 459-478.

TSAL, Y., LAVIE, N. (1988). Attending to color and shape: The special role of location in selective visual processing. Perception \& Psychophysics, 44, 15-21.

WERTHEIMER, M. (1923). Untersuchungen zur Lehre von der Gestalt. Psychologische Forschung, 4, 301-350.

WEYMouTH, F. W. (1958). Visual sensory units and the minimum angle of resolution. American Journal of Ophthalmology, 46, 102-113.

Wolfe, J. M., Cave, K. R., \& Franzel, S. L. (1989). A modified feature integration model for visual search. Journal of Experimental Psychology: Human Perception \& Performance, 15, 419-433.

YEH, Y.-Y., \& ERIKSEN, C. W. (1984). Name codes and features in the discrimination of letter forms. Perception \& Psychophysics, 36, 225-233.

YNTEMA, D. B. (1963). Keeping track of several things at once. Human Factors, 5, 7-17.

\section{NOTES}

1. All post hoc comparisons reported in this article were computed with a Bonferoni $t$ test and are significant at $p<.05$.

2. In addition to the subjects who performed the focused attention task, we had another group of 8 subjects who indicated the groups that they perceived in each of the displays and rated the strength of grouping in each of the displays. This group was run to ensure that the ratings obtained from the subjects who participated in the focused attention experiment were not biased by their performances. The subjective ratings obtained from the nonexperimental group did not differ significantly from those obtained from the experimental group. Therefore, it would appear that both the groups that were perceived in the displays and the strength ratings are relatively robust.

3. An alternative to our suggestion of a graded grouping phenomenon would be an all-or-none grouping process in which target/distractor grouping trials were mixed with trials on which the targets and distractors were not grouped. Thus, with the all-or-none process the intermediate size response-compatibility effect obtained in the MS control conditions would be due to a mixture of grouping and nongrouping trials rather than an intermediate level of grouping. One way to distinguish between the graded and all-or-none grouping models is to examine the RT probability density functions for the same-object, MS control, and different-object conditions, to determine whether they pass through a common (fixed) point. Falmagne (1968) first noted the fixed-point property of binary mixture distributions. According to this property, all linear combinations of two partially overlapping probability density functions (e.g., grouping trials and nongrouping trials) must pass through the same fixed point. The fixed-point property was not satisfied by our data in any of the three experiments. Therefore, the data are inconsistent with a model in which the proportion of grouping and nongrouping trials varies as a function of our display manipulations. Instead, the data are consistent with a model in which grouping changes in a graded fashion from the same-object to the MS control to the different-object condition.

4. As in the previous experiment, ratings of grouping strength and the number of groups in each display were also obtained from 8 subjects who did not perform the focused attention task. There were no significant differences in the ratings obtained from the two groups of subjects.

(Manuscript received September 5, 1990; revision accepted for publication March 22, 1991,) 